EPJ Web of Conferences 45, 01073 (2013)

DOI: $10.1051 /$ epjconf/20134501073

(C) Owned by the authors, published by EDP Sciences, 2013

\title{
The temperature fields measurement of air in the car cabin by infrared camera
}

\author{
M. Pešek ${ }^{1, a}$ \\ ${ }^{1}$ Brno University of Technology, Faculty of Mechanical Engineering, Energy Institute, Technická 2896/2
}

\begin{abstract}
The article deals with the temperature fields measurement of air using the Jenoptic Variocam infrared camera inside the car Škoda Octavia Combi II. The temperature fields with the use of auxiliary material with a high emissivity value were visualized. The measurements through the viewing window with a high transmissivity value were performed. The viewing windows on the side car door were placed. In the rear car area, the temperature fields of air on the spacious sheet of auxiliary material were visualized which is a suitable method for 2D airstreams. In the front car area, the temperature fields in the air were measured with the use of the measuring net which is suitable for 3D airstreams measuring.
\end{abstract}

\section{Introduction}

The temperature fields measurement by the infrared camera is very effective and quick way to measure the temperature. The infrared camera is used for this purpose in many scientific disciplines and industrial applications, especially in the field of heat transfer and thermodynamics [1]. The thermography is mainly used for measuring the surface temperature but this article tries to describe the measurement of temperature field in the air [2]. The infrared camera allows measuring the static conditions and the monitoring of dynamic processes but in the comparison to other methods of measurement (e.g. the measurements of the net of thermocouples, interferometry, planar laser-induced fluorescence, etc.) is more suitable by usage outside the laboratory. The temperature visualization by the infrared camera also allows the deeper understanding and indentifying connections in the measuring processes during the monitoring of a variable temperature field. This method of measurement of temperature fields in the air can be used in many fields of heating and cooling [3]. With the use of the viewing window the method can be also applied for measurements of temperature fields in small closed spaces, such as in cabins of means of transports, air-conditioning units, or in areas which is not suitable for operation staff and others [4].

\section{The measuring method description}

The method of measurement of the temperature fields is based on the usage of the auxiliary material on which the temperature fields are displayed. This auxiliary material is placed to the air-stream of monitored area [5]. The convection heat flow changes the surface temperature of auxiliary material which is measured by the infrared camera. The surface temperature of this support material can be taken as the air temperature of this area. For twodimensional (2D) airflow it is suitable to use the spacious sheet of auxiliary material. For three-dimensional (3D) airflow it is necessary to use the measuring net that does not restrict the air flow so much as the compact sheet. In order to use this method for measurements in small closed space, the temperature field in the air has to be measured through a visor. The visor ensures the noninfluence of the measuring object by the measuring equipment that includes the infrared camera, tripod-base stand, operation staff, etc. In some cases of measuring of the temperature fields the device for measuring is also too voluminous and the usage of viewing window is the only suitable way.

\section{The measuring stand description}

The stand for measuring of the temperature field in the air in the car cabin using an infrared camera consists of the car, the infrared camera with the accessory, the auxiliary materials for displaying $2 \mathrm{D}$ and $3 \mathrm{D}$ temperature fields and the visor.

\subsection{The vehicle}

The measuring of the temperature fields in the car cabin was performed in the common car of the Czech Republic. It is Škoda Octavia Combi II, 2.0 TDi made in 2007 of Škoda factory from the Volkswagen concern, figure 1. The car is in the design of Elegance model which

am.pesek@email.cz 
indicates an advanced dual air conditioning. Air conditioning outlets are located at the legs area (4 pcs), for windscreen heating, four pieces for air conditioning in front section and two outlets are situated in the centre rear console for the rear section.

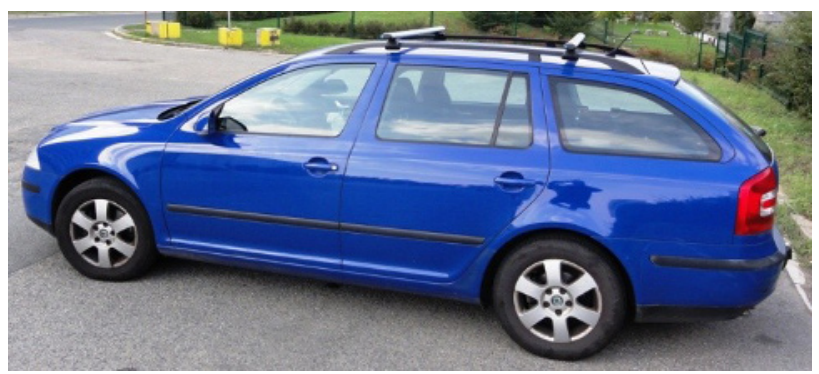

Fig. 1. Škoda Octavia Combi II 2007

\subsection{The infrared camera}

The measurement was done by the infrared camera (IR) VarioCam from Jenoptic corporation. VarioCAM is a robust, handheld infrared camera for precise real-time thermography. Based on an uncooled microbolometer array, infrared camera was specially conceived for use in preventive maintenance. The camera is especially suitable for industrial use due to the compact design and the high degree of protection, see figure 2 .

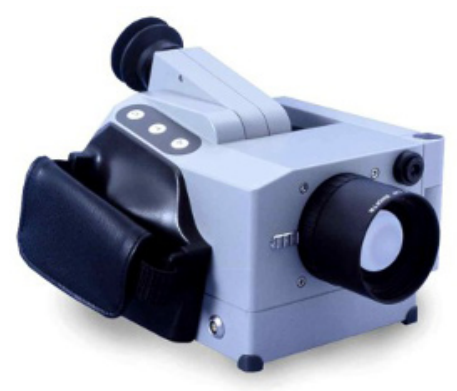

Fig. 2. Jenoptic - VarioCam infrared camera [6]

For the measurement of temperature fields in the car cabin the standard lens $\left(32^{\circ} \mathrm{Hx} 25^{\circ} \mathrm{V}\right)$ was used. Parameters of the infrared camera are shown in table 1.

Table 1. Technical data of IR Jenoptic - Variocam [6]

\begin{tabular}{|l|l|}
\hline Spectral range & $8-13 \mu \mathrm{m}$ \\
\hline Resolution & $320 \times 240$ pixels \\
\hline Detector & Uncooled \\
\hline $\begin{array}{l}\text { Temperature } \\
\text { measurement range }\end{array}$ & $-40 \ldots 1.200{ }^{\circ} \mathrm{C}$ \\
\hline IR image frequency & $50 \mathrm{~Hz}$ \\
\hline $\begin{array}{l}\text { Measurement } \\
\text { accuracy }\end{array}$ & $\pm 2 \mathrm{~K}, \pm 2 \%$ \\
\hline Analogue interfaces & $\begin{array}{l}\text { PAL/NTSC-FBAS and } \\
\text { S-Video, headset }\end{array}$ \\
\hline Image storage & $\begin{array}{l}\text { CF card, optional } \\
\text { FireWire }\end{array}$ \\
\hline
\end{tabular}

The radiation temperatures of surroundings for all measurements was determined by the infrared thermometer Testo 830-T2, figure 3. The Testo 830-T2 has additionally a 2 point laser sighting with the $-30{ }^{\circ} \mathrm{C}$ to $+400^{\circ} \mathrm{C}$ measuring range. The measuring accuracy is $\pm 1.5{ }^{\circ} \mathrm{C}$.

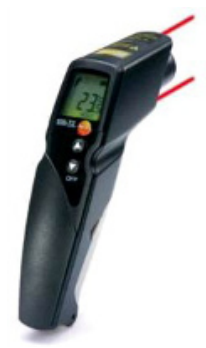

Fig. 3. Testo 830-T2 infrared thermometer [7]

\subsection{The auxiliary material for visualizing}

The auxiliary material is used for visualizing the air temperature. This material for infrared measurements of air temperatures should have especially high emissivity in order to the high accuracy and because of the reduction of the noninfluence of the ambient radiation temperature. The surface of the auxiliary material must be fully planar in order to eliminate the measurement inaccuracy and its size is proportional to the temperature field to be visualized. As an auxiliary material the planar office paper with high the emissivity value was chosen [8]. The emissivity of the planar office paper of $80 \mathrm{~g} / \mathrm{m}^{2}$ was measured to the value of 0.96 . The planar office paper has a no-reflection surface, low heat capacity, low heat conductivity and minimal thickness. These quantities have an influence to dynamic properties of the measuring method and they are expressed by the time constant.

The auxiliary material can be used as a spacious sheet or in the form of measuring targets. The visualization of temperature fields in the air by the thermovision on a spacious sheet of auxiliary material is suitable only for measuring of temperature fields in two dimensional airflows. The measuring of temperature fields in 2D airflows can be imagined as the measurement where the compact auxiliary material (compact sheet) is parallel with streamlines. The visualization of temperature fields in the air by the thermovision on measuring targets in the net is especially suitable for measuring of temperature fields in three dimensional airflows. In notion of measuring of temperature fields in 3D airflows it can be imagined the measurement where the auxiliary material (measuring targets) is not parallel with streamlines, for example when more heat sources are used, or alternatively, where is used a rotate circle airstream and so one [9].

\subsection{The viewing window}

For correct measuring of temperature fields in closed spaces (car cabin) through a transparent material, the viewing window material properties is necessary to be known. The main important property of transparent 
material is its transmissivity, the ability to transmit an infrared radiation that the infrared camera detects. The polyethylene foil, in a thickness of $0.05 \mathrm{~mm}$ as the visor material, was chosen. The polyethylene foil transmissivity for the suitable wavelength range was determined by the same infrared camera. The transmissivity of this polyethylene foil was measured to the 0.90 value.

\section{The experiment equipment description}

The measurement of temperature fields by IR camera was carried on the front and rear seats the Škoda Octavia II by the IR camera VarioCam. The infrared camera was placed on the stand or it was used for the hand-held measuring with pressing the camera to the visor. The measurement of radiation temperature inside and outside the car was measured by the infrared thermometer Testo 830-T2. To measure at the rear seats area, the compact sheet of the auxiliary material was used and for the measurement at the front seats area the new measurement net with targets was applied. The auxiliary material for targets and the compact sheet was made of the planar office paper. Measurements were performed through the polyethylene visor. The car glass window was rolled down into the door and the free visor was equipped by the polyethylene sheet to close the interior space from the exterior space. The plastic foil on the door was attached by an adhesive tape.

\subsection{The rear part of car}

For the experiment the ventilation outlet of the center console for air conditioning of rear seat was chosen, figure 4 .

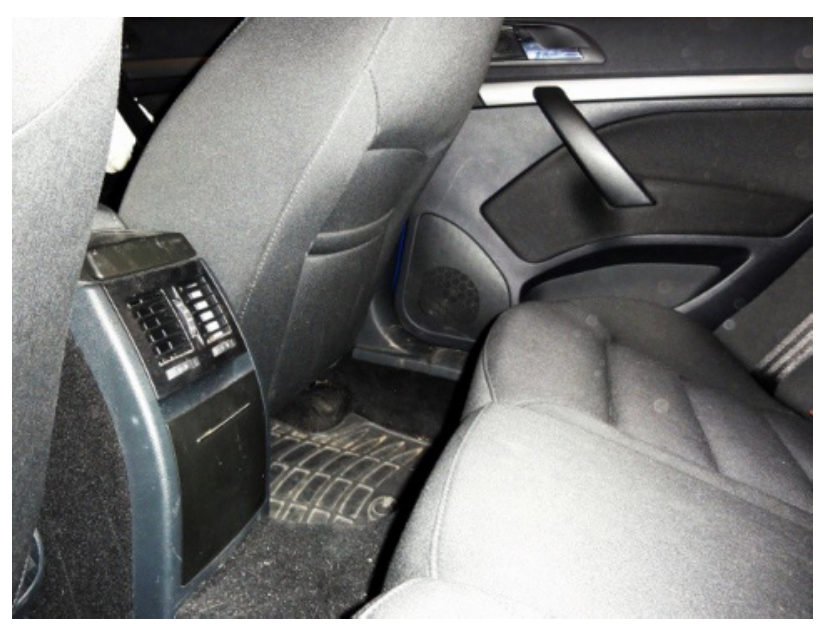

Fig. 4. Air-conditioning mouth outlet for rear row seats in Škoda Octavia II

The size of auxiliary material was modified according to the geometry of the rear row of seats. The geometric shape of the paper sheet was a rectangular trapezium with the bases of lengths of $60 \mathrm{~cm}$ and of $80 \mathrm{~cm}$ and the height of $80 \mathrm{~cm}$, figure 5 .

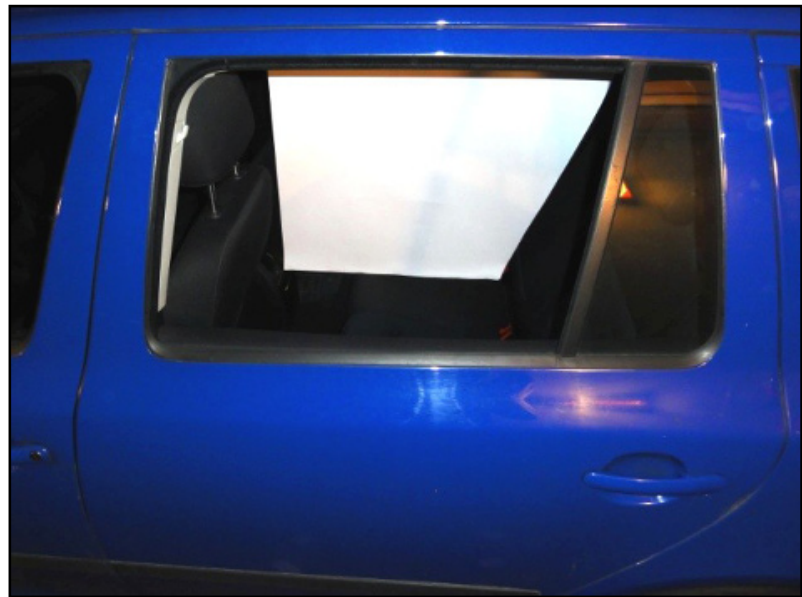

Fig. 5. Auxiliary material position before the mouth outlet of rear seats

The paper sheet was attached to the car cabin roof and the bottom was equipped by weights to its perfect plane balancing. The measuring of temperature fields was carried out by the left rear car door.

\subsection{The front part of car}

For the measuring in front of the vehicle cabin, the measuring net with dimensions of $600 \times 480 \mathrm{~mm}$ was manufactured. The measuring net consists of an aluminium frame and measuring targets that are attached on the cords, figure 6 .

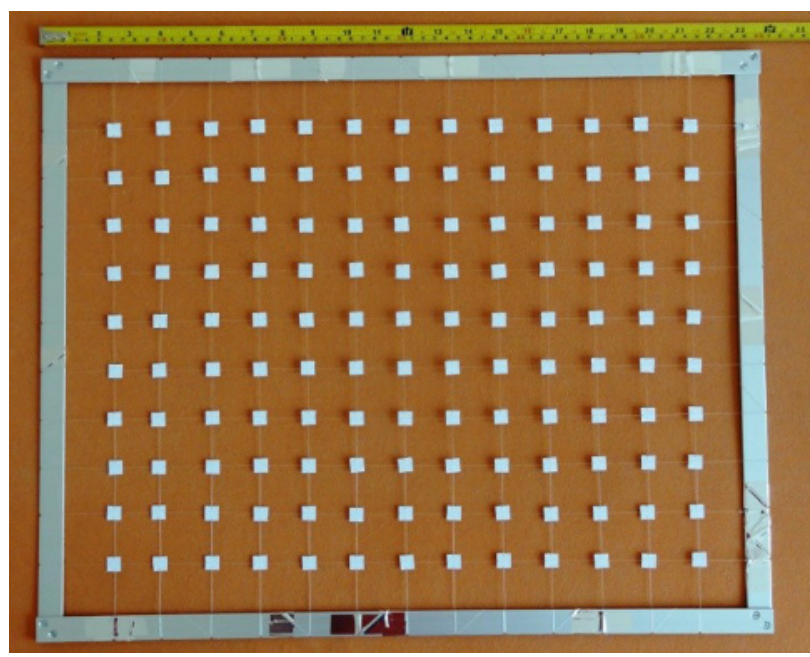

Fig. 6. The measuring net

The measuring targets are situated equidistantly with the distance of $4 \mathrm{~cm}$. The size of measuring targets should be chosen such that their sizes are $3 \times 3$ whole pixels on the thermogram. To guarantee this condition the measuring targets were suggested to be $5 \times 5$ pixels minimally. The measuring target was calculated as $12 \times 12 \mathrm{~mm}$ in order to measuring distance (from the infrared camera to measuring frame), from horizontal and vertical fields of view of using lens and from the resolution of the VarioCam infrared camera. The paper targets are situated on both the sides of cords on measuring net by an 
adhesive. All the measuring targets are situated on cords and targets and cords have together only $7.7 \%$ of total area of the frame.

\section{Results}

The visualization of temperature fields in the air the car cabin was done for a different intensity of ventilation and the different air temperature. Temperature fields in the car cabin were scanned from several viewing angles and different distances of the infrared camera in front of the polyethylene window. Also the case where the camera lens was pressed directly to the window of polyethylene (during the handheld measuring) was considered to prevent the non-uniform picture of the outside environment which could be shown on the polyethylene window. In the handheld measurement, the polyethylene foil in viewing window at maximum stretch is also ensured. The measurements in several different settings of mouth outlet air flowing were done. The visualization of hot airflow (heating) and cool airflow (cooling) was recorded. The infrared measurements were done in the infrared camera stable state, for the inside temperature field stable state, and also after the autocalibration of the camera.

\subsection{The measuring in the rear part of car}

For the rear row of seats the central mouth outlet on the spacious sheet of paper was visualized. The mouth outlets settings were parallel with the auxiliary material and therefore the method for displaying 2D temperature field in the air could be used. The hot airstream from mouth center outlets in the middle positions $\left(60^{\circ}\right.$ from the horizon) was displayed, figure 7 . Two centre outlets were only open, the other outlets were closed mechanically and the airstream was set up through this outlets.

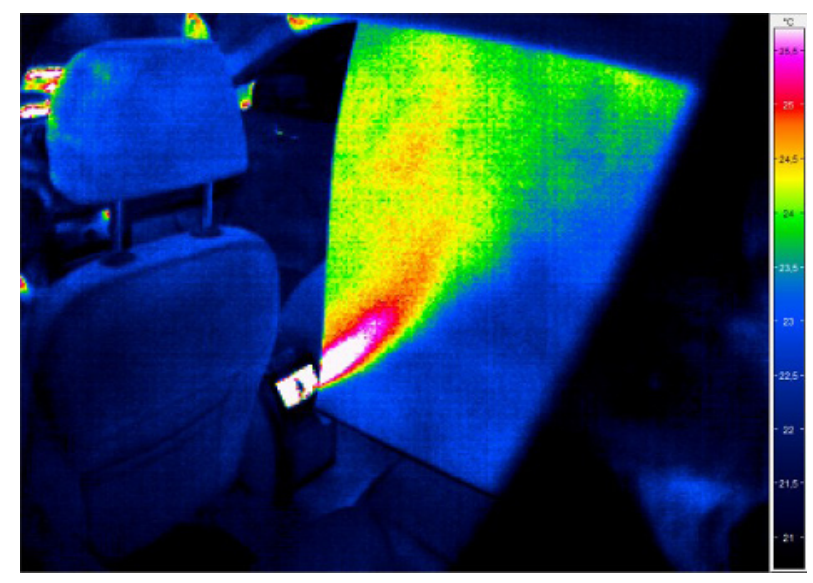

Fig. 7. The thermogram of measured temperature field in 2D hot airstream at rear row of seats from the infrared camera on the tripod stand

From figure 7 it is obvious that the hot airstream does not interfere to the area of passengers and goes up very quickly. The mean radiation temperature inside the car was $22.5^{\circ} \mathrm{C}$ and from the thermogram it is evident that it was almost homogenous. In the thermogram the nonhomogenous areas are shown, but it is due to the reflections from working devices and the air conditioning distribution leaks.

After the temperature re-stabilization in the car cabin to the mean radiation temperature additional measurements were carried out with the same settings in the cooling mode. Only the centred outlets were set to the minimum slope $\left(30^{\circ}\right.$ from horizon), figure 8 . The thermograms shows that the cold airstream is directly interfered to the passengers area, where is absorbed by the seats and it does not already distribute.

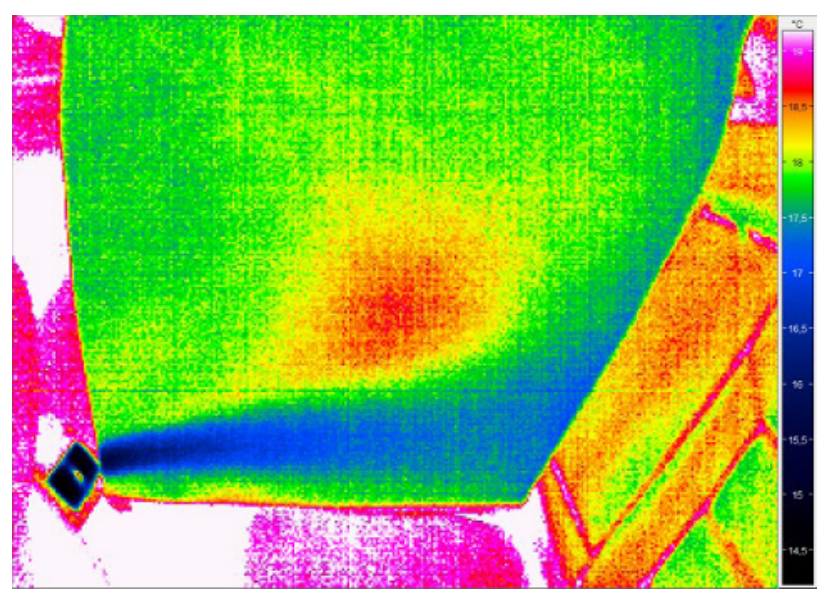

Fig. 8. The thermogram of measured temperature field in $2 \mathrm{D}$ cold airstream at rear row of seats from infrared camera on the hand-held measuring

\subsection{The measuring in the front part of car}

The imaging of air temperature fields in front of car was performed on the measuring net which was situated in the front passenger area and in the space between the driver and the co-driver area.

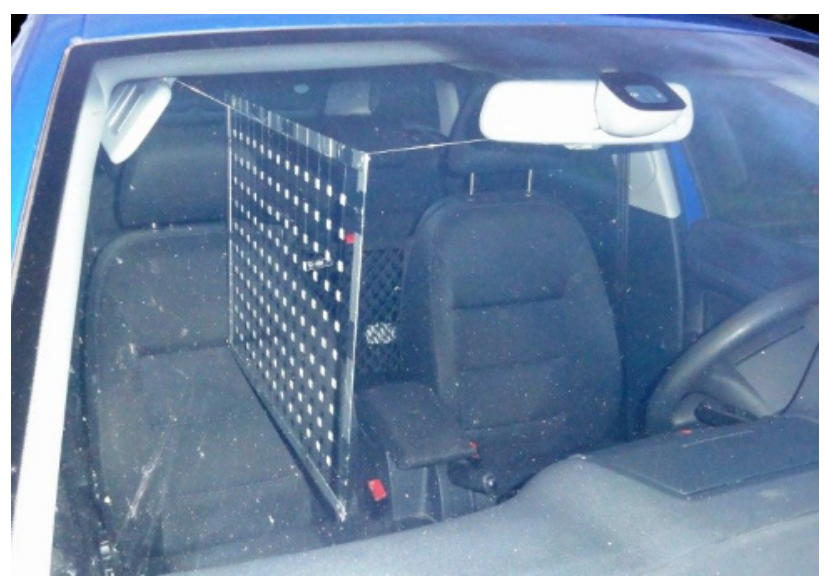

Fig. 9. The placement of measuring net in the front passenger area

The measuring net was hung in the axis of the seat of the head passenger area at the right angle to the dashboard, figure 9, and the temperature fields of two air outlets for this front passenger area were monitored. The mouth 
outlets are located at the side window and in the centre console of the dashboard. The airflow was directed to the head area of front passenger. The second location of the measuring net was in the area between the driver and the co-driver in the axis of the car at the right angle to the dashboard. The air flowing from the four air mouth outlets from the dashboard to this area was visualized, figure 10. Other mouth outlets were closed for this measurement mechanically or by the car computer settings.

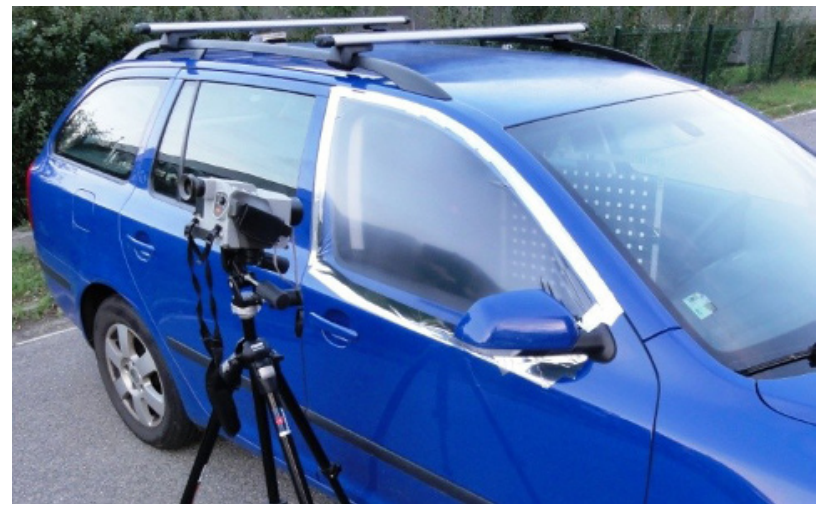

Fig. 10. The placement of measuring net between the front passenger area and the driver area

The original visualization of the hot air flow in the front passenger area is shown in figure 11 .

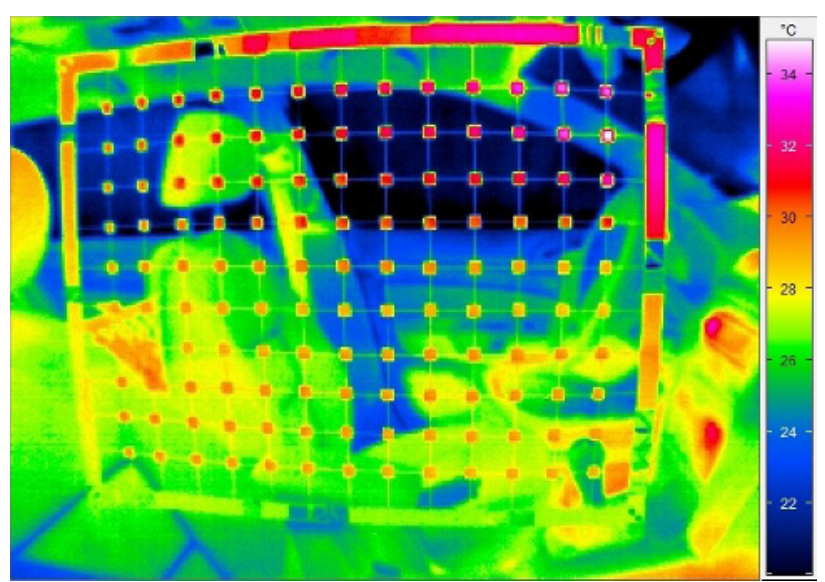

Fig. 11. The original thermogram of the hot air stream measuring in the front passenger area by hand-held measuring

The thermogram was carried out from the hand-held measuring of pressing the infrared camera to the viewing window. All mouth outlets were set horizontally and in the angle of $25^{\circ}$. The measurements were performed in the outside space in mean radiation temperature $5{ }^{\circ} \mathrm{C}$ in cloudy sky. Inside the car the mean radiation temperature was $23{ }^{\circ} \mathrm{C}$. Because in the original thermogram it is not clearly evident the distribution of temperature field, it was necessary to modify the thermogram in software Surfer 10.0. Modified thermogram of temperature distribution is shown in figure 12 .

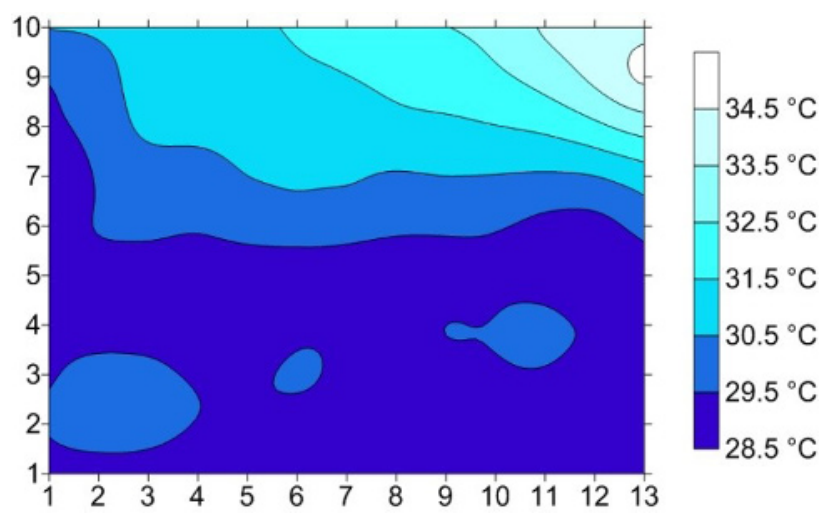

Fig. 12. The cut of the modified thermogram of the hot air stream measuring in the front passenger area by hand-held measuring

After stabilizing the temperature inside car, the measurements in the central axis of the car were performed with settings of middle outlets parallel to the net and by setting up side mouth outlets to maximum angle $\left(60^{\circ}\right)$ to the net.

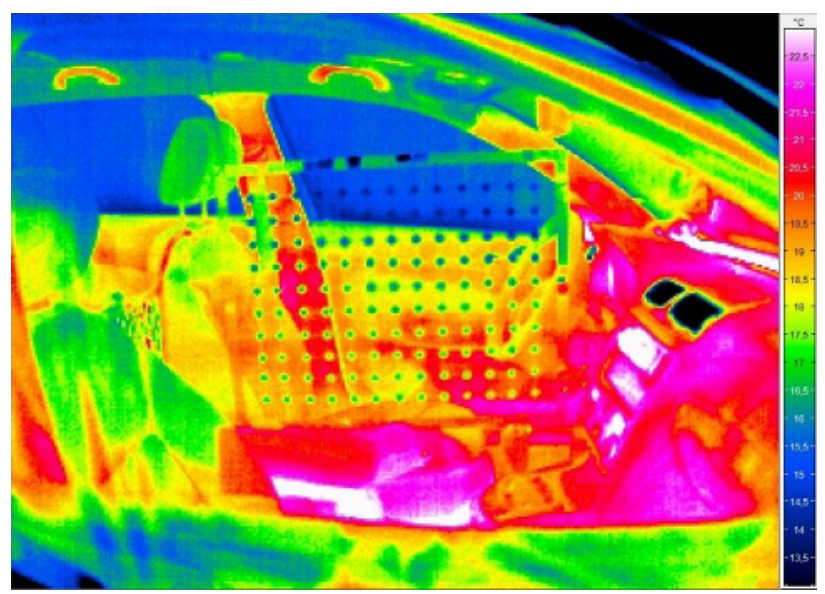

Fig. 13. The original thermogram of the cold air stream measuring between the front passenger and driver area by measuring from the tripod stand

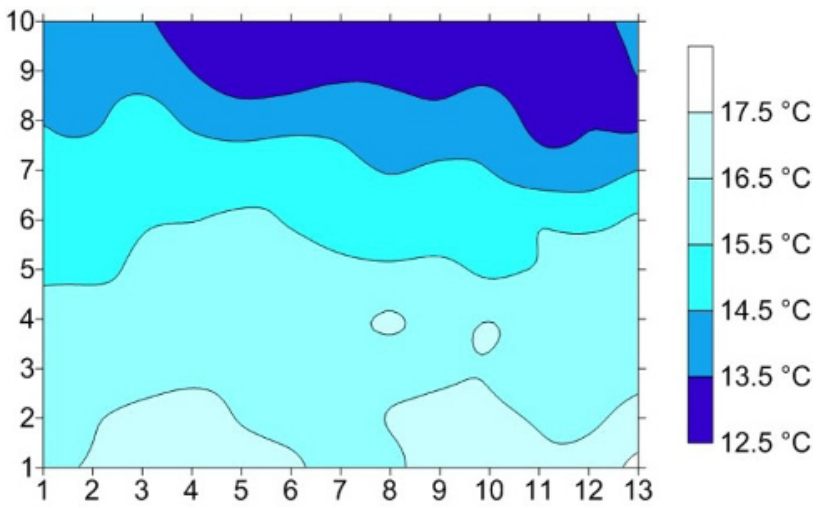

Fig. 14. The cut of the modified thermogram of the cold air stream measuring between the front passenger and driver area by measuring from the tripod stand

From horizontal, the airflow was set to $25^{\circ}$ and the measurement was carried out in the cooling mode. The 
mean radiation temperature was the same as the previous measurement and the measurement was done from the base tripod-stand. The original thermogram is shown in figure 13 and the modified thermogram is shown in the figure 14 .

\section{Conclusions}

The measurement of temperature fields in the air by an infrared camera is one of possible methods how to measure the temperature fields in the air. This method of measuring is not possible only in large free environments but it is also convenient for small closed spaces where is the measurement done through the viewing window and where is needed a complete knowledge of the air temperature distribution. This method is also very suitable in comparison to other methods of the temperature air measuring because of applicability outside the laboratory.

The shown experiments demonstrate the possible applications of the method in the measurement of temperature fields in the car cabins through the viewing window and it indicates a possible verification with the numerical flow models which are particularly used to design air ducts in the cabins of vehicles. From the presented experiment it is demonstrable that the usage of a spacious sheet of material is suitable only for two dimensional airstreams. For three dimensional airstreams the measuring net is needed to use.

\section{Acknowledgement}

The support of this research from the standard project FSI-S-11-6 "Human Centered Design" is gratefully acknowledged.

\section{References}

1. M. Vollmer, K. P. Möllmann, Infrared Thermal Imaging: Fundamentals, Research and Applications (2010)

2. T. L. Williams, Thermal Imaging Cameras: Characteristics and Performance (2009)

3. W. Minkina, S. Dudzik, Infrared Thermography: Errors and Uncertainties (2009)

4. M. Pešek, M. Pavelek, International Symposium on contamination control, 84-88, (2012)

5. J. Fišer, R. Mlčák, M. Pavelek, M. Jícha, Exp. Fluid Mech., 36-41, (2008)

6. INFRATEC. Product catalog: VarioCam [online]. [cit. 2012-09-24]. Available from: http://www.InfraTec/InfraTec.de

7. TESTO. Product catalog: Testo 830-T2 [online] [cit. 2012-09-24]. Available from: http://www.testo.com

8. M. Pešek, M. Pavelek, Exp. Fluid Mech., 888-892 (2011)

9. M. Pešek, M. Pavelek, QIRT, 212-218 (2012) 